\title{
Development Status and Prospects of Punch physical security systems
}

\author{
Xin-peng $\mathrm{Li}^{1, \mathrm{a}}$, Chao-yong Guo ${ }^{2, \mathrm{~b}}$ \\ ${ }^{1}$ School of Ordnance Engineering College, Hebei Shijiazhuang 050003, China \\ 2 School of Ordnance Engineering College, Hebei Shijiazhuang 050003, China \\ a15030179930@163.com, buocy1963@163.com
}

\begin{abstract}
Based on the phenomen of personal safety accidents of punching machine , this paper analyzed the factors of press working process personal safety incidents, described and compared the advantages and disadvantages of the safety device at this stage. Summarize some of these security issues still unresolved safety device, proposed the safety mechanism on this basis, and describes its concept.
\end{abstract}

Keywords: Punching machine, personal security systems,description

\section{Introduction}

Stamping occupies an important position in machining, stamping machinery processing high efficiency, good quality, low cost, widely used in metal products industry, which brings a high industrial output for the metal products industry. However, with the widespread use of stamping machines, Some accidents are frequent. Because during the operation of punching machine in need of workers with the use of hands and feet, and intense concentration, and repeat the operation tedious, it is prone to fatigue, resulting in lack of concentration, and thus the occurrence of accidents. According to statistics, there are thousands of wounding accident occurred everyears especially in some state-owned enterprises, township enterprises often finger, injury accident, which not only caused great physical and psychological damage to the workers, but also brought great economic losse to the company . Therefore, we need to design a safety device to reduce the occurrence of accidents punching machine and ensure the safety of operating workers. In summary, the study of the press to protect the personal safety of the system is a very important and meaningful things.

\section{Factors of stamping safety accidents}

\subsection{Human Factors}

Press work is a continuous iterative process, the press operator needs hands rhythmically repetitive movements, this process is tedious and requires highly concentrated of operator's attention, so workers can easily lead to fatigue, inability to concentrate, unresponsive, movement disorders, thereby increasing the incidence of accidents.

New employees lack of experience and work stress, uncoordinated operations is also a human factor. At the same time,the health reasons while staff illness and lack of sleep is also an important factor in causing the accident.

\subsection{Equipment factors}

(1) In accordance with relevant stamping machinery safety requirements, the operator's hands can not feed into the stamping module reclaimer,the operator must use security pliers or safety clip, magnetic safety hand like reclaimer. However, in practical work, some employees in order to facilitate taking a direct hand into the module feeding, largely increases the probability of accidents.

(2) Press its own security risks. Such as some press need to use the press foot, it might have an accident if hands and feet with the bad; some punch with a single-phase control, a hand control switch, a hand feeding, with the bad hands will have an accident; some press punch faster or slower, and even rushed for operator safety pose a serious threat.Positive clutch did not haye stop punching machine 
function during descent, which itself is a security risk. Clutch, brake, electrical component failure due to security risks.

(3)Security systems of the press have security risk. Some press not equipped with safety protection system; some press security systems are too simple , protective effect is not obvious; some protection systems directly in fail state, could not be replaced.

\subsection{Envirnmental factor}

(1) Stamping plant operation safety standards are not clear, press safety inspections and maintenance may not be implemented, one more work with less staff.

(2) In the press shop, the noise is a big risk factor. Long-term noise in the environment, the nervous system of workers will have a serious impact, easy for staff to produce feelings of anxiety, irritability, leading to inattention of staff . Thereby increasing the probability of occurrence of accidents.

(3) Press shop lighting inadequate. In the irradiation range punching machine with insufficient lighting would have a shadow in the work area during irradiation; simultaneously with its illumination and general illumination contrast is too strong, can not meet the workers 'demands for better brightness and reduce the workers' eyes sensitivity, easy to make the eyes appear worker fatigue, pose a safety hazard.

\section{Analysis safety systems of stamping machine}

Depending on the different processing object of the press safety protection system can be divided into: direct protection system and indirect protection system. In addition there is a type of protective device is primarily designed to avoid the start, that means both hands simultaneously.

\subsection{Direct protection system}

Direct protection system's processing target is person, from the perspective of people to protection.

(1) Push hand safety device

On approaching the upper and lower die molding process, the safety device use the rocker arm (safety bar) and the fan door to sweep the hands and fingers within this zone in mechanically way, known as pushing hands safety devices. Means of such a device is simple, because the front end of the rocker arm move with circular, if the swing is large, open at both ends is large, resulting in a lack of protection of the central portion. Thus, the swing set is not too large; if the swing must be larger, in the front end of the arm means transparent plate so that the remaining part of the risk of narrowing processing point, you can get a better protective effect.

(2) Handle safety device

Handle safety device can connect the worker's hands and pulleys attached slider with ropes . Thus, when the slider down use rope connected with hand, you can hand out of the danger zone.The most important thing of handle safety device is the length of the rope should be appropriate, properly installed.

(3) Barrier protection

It can be used in rigid clutch press and friction clutch press . The principle is between the operator and the danger zone, or set a fence around the protected area, Movement with the slide movement of the press . When the slider return, open the fence, can be installed, unloading, the security fence closed when the slider down which can cut the hand enter between the upper and lower mold. Security fences are generally suitable for continuous stroke. When the pressure mechanical failure and a false start cause the slider punch,due to the chain between the fence and the slider movement , it can play a protective role..

(4) Fixed fence protection

Fixed guards are used permanently. It ensures the operator to work safely outside the danger area or dangerous machinery. It uses a barrier, or in the form of a plastic cover member, best suited for continuous stamping blanking processing.

The advantages are: a permanent installation, low investment, long life, no dangerous protrusions. 
Restrictions: may have difficulty entering the area for maintenance, it is easily removed and untested.

\subsection{Indirect protection system}

The process of the indirect protection system is punch, through the detection of dangerous situations to stop the stamping process.Indirect protection system includes sensing system, control system, execution system and alarm system. Induction system is mainly awareness of the dangers that can distinguish between normal and dangerous situations, and the perception of information is transmitted to the control system. Control system receives sensor signals, by the signal processing to achieve the implementation of the system and the alarm system control functions. Execution system is mainly to complete braking in dangerous situations. Alert system for dangerous situations can alarm function, provide a warning to the operator.

(1) Optoelectronic protective devices

Setting screens between the operator and the upper and lower molds the around of danger area,forming a detection zone having detection capability. When the operator's body or some kind of hand-held object enters the detection area , control means send a stop signal, so that an immediate cessation of the slider down to protect the goal. This device is mainly used for double-action drawing, continuous processing and foot switch operation, due to the pressure and prevent the slider failure caused by secondary whereabouts invalid.

Advantages: high reliability; large electrical immunity.

Applicability limits: space; often also need to add a fixed guards.

Single-beam and multi-beam system: This system is formed around the perimeter of the machine to control the inlet channel. They are designed to detect the operator body designed. Use mirrors to produce the L or U-shaped form of protection.

\section{(2) Laser Scanner}

Laser scanner protect the area around the dangerous machine. Whenever it detects a diameter greater than $70 \mathrm{~mm}$ objects (such as: feet, legs), the device will start the stop signal machine safety control system. In addition, these devices have advance warning function, so that people before entering the danger zone can be warned to avoid unnecessary downtime.

Advantages: easy to shape complex programming protected areas, protected area can be expanded.

Applicability Limitations: sensitive to environmental pollution.;

(3) Capacitance protection device (also known as the human body sensing device)

Between the operator and the dangerous area, set capacitor which has certain capacitance to the earth as the sensing element. through the length change when close to sensitive components during loading and unloading , to change the size of the capacitor to ground, and then through the amplifier, so that the machine can be stopped or not started. Since the inductive protection greatly influenced by human factors and venues(such as wearing different socks, gloves and other new and different), use very inconvenient.

(4) Air curtain protection device

Between the operator and the danger area, set the air curtain. Once the operator's hand, body or other objects blocking the air curtain, it starts off control circuit means, stop or start the slide movement. The above automatic protection device does not affect the line of sight of the spiritual and the operator, thereby reducing mental fatigue. But for the slider secondary failure caused by falling invalid.

\subsection{Both hands simultaneously means}

Using hands hold both buttons simultaneously or operating handle. Making the slide drop by electromagnetic force, spring force, air pressure near the human or clutch. It requires the operation buttons on the outside according to press the emergency stop performance given safe distance. So that when the slider down, forcing operator to leave the danger zone, to prevent accidents when release handle and after starting to take things between the upper and lower molds.This operation must be hands button chain, most are used to control only one operator to configure the machine. Hand controls often installed with other security equipment, widely used in the production facilities. 
Advantages: low investment, small footprint, easy to install, easy to start.

Applicability restrictions: only provide hand protection is not provided to third parties and to protect potential ergonomic major conflict, such as the slider caused by mechanical failure secondary whereabouts invalid.

\section{Summary}

\subsection{Analysis of the above security system}

(1) hand operation safety device is to start from the consider protective measures stage press. The safety device can only provide a dual protective effect at startup,after startup there will not have any role in the protection. In practice, even if the addition of both hands operated protection device, due to the effect of employees, number of accidents still occur frequently.

(2) direct protection system's central idea is prevent the hand outside the hazardous space in the form of compulsory mechanical when the slider in the process of decline.this protection system between the upper and lower molds have a mechanical object in motion, which itself is dangerous, while repeating the shaking of the mechanical object is easy for the operator to dizziness, fatigue feeling.

(3) Indirect protection systems are in working phase of the press provides security protection. But after it detects a dangerous situation, the action is to block input power, and then let the slider stops naturally. Even without power input, the slider due to inertia will continue to decline, it will also cause some injuries.

\subsection{Summary}

Based on the above analysis, now there have some protection system in domestic and foreign at the start-up phase as and the sessions of the press. However, these protective systems can not completely exclude the dangerous situation. A typical security risks are:the problem of the punch's natural fall after it down block. Now we need a new security system. The system can be implemented after detecting dangerous, so the slider directly and quickly braking. The system is to start in the most direct way to prevent the occurrence of danger from hazards, reaction speed. At the same time when the press is working properly, it will not affect the operation of other workers.

\section{Acknowledgments}

Corresponding author is Xin-peng Li,whose phone number is 15030179930.

\section{References}

[1] REN Li-ming. Forging Machine Personal automatic protection system design [D]. Hebei University of Technology master's degree thesis, 2011.

[2] SHEN Lan.Present Situation of mechanical pressure's safety protection device[J]. Metalforming Equipment \& Manufacturing Technology, 2005: 10-18.

[3] PENG Jun-wang.Stamping hand injury accident prevention [J] Safety Technology, 1997, (1): 12.

[4] LIU Yan,GONG Sui-li,MA Yan-jun.Development of high sensitivity Machine Security System [J] Infrared Technology, 2005, (11): 45-46.

[5] YANG Qun.Mechanical press operations for the safety [M] Beijing: Electronic Industry Press, 1990: 109-112.

[6] XI Lei.Punch Automatic Protection System [D]. Harbin University of .2009.

[7] SHI Yi.The main risk factors which machine labor protection .2013 (6): 133. 